\title{
Evaluation of Isotopic Diagnostics for Subsurface Characterization and Monitoring: Field Experiments at the TAN and RWMC (SDA) Sites, INEEL
}

\author{
Principal Investigators: \\ Donald J. DePaolo Tel: 510/495-2228, Fax: 510/486-5686, email: djdepaolo@lbl.gov \\ B. Mack Kennedy, Tel: 510/495-6451, Fax: 510/486-5686, email: bmkennedy@lbl.gov \\ Lawrence Berkeley National Laboratory
}

Co-Investigators: Mark Conrad (LBNL)

Eric Miller and Thomas Wood (INEEL)

\section{$\mathbf{1 . 0}$ INTRODUCTION}

This research is aimed at improving methods for characterizing underground contamination sites and for monitoring how they change with time. Particular emphasis is placed on identifying and quantifying the effects of intrinsic remediation and verifying the efficacy of engineered remediation activities.

Isotopic measurements of elements such as $\mathrm{C}, \mathrm{O}, \mathrm{H}, \mathrm{He}, \mathrm{Cl}$, and $\mathrm{Sr}$, which are present in groundwater and soil gas, provide a quantitative measure of material balance. They can be used to identify the sites of origin of contaminants in groundwater, and to determine if contaminants are being destroyed as a result of natural processes or engineered processes. Isotope ratios also can be used to trace the migration of fluids that are pumped down wells to destroy or confine underground contaminants, such as steam and grout, and they can be utilized to diagnose what chemical reactions are occurring underground and what materials are reacting. For example, destruction of TCE usually produces carbon dioxide, but carbon dioxide can also come from dissolution of calcite.

There are many isotopic ratios that can be measured in groundwater and vadose zone gas that could be valuable for characterizing remediation sites and monitoring remediation activities; We concentrate on a few that are particularly useful for the problems being addressed at the TAN (Test Area North) and RWMC (Radioactive Waste Management Complex) sites of the Idaho National Engineering Laboratory. The isotopes we are using are ${ }^{13} \mathrm{C},{ }^{14} \mathrm{C},{ }^{3} \mathrm{He},{ }^{87} \mathrm{Sr},{ }^{37} \mathrm{Cl}$, and ${ }^{18} \mathrm{O}$.

\subsection{DESCRIPTION OF FIELD SITES}

\subsection{The Test Area North (TAN) site}

From 1955 to 1972 a variety of waste materials, including low-level radioactive isotopes, sewage, and chlorinated solvents, were disposed of in a 310-ft well both above and below the water table. The resultant plume of TCE, DCE, ${ }^{90} \mathrm{Sr},{ }^{137} \mathrm{Cs},{ }^{3} \mathrm{H}$, and some other contaminants in the Snake River aquifer, is moving southeastward at the rate of about $100 \mathrm{~m} / \mathrm{yr}$. The plume, which is mapped using TCE concentrations (Figure 1), extends about $2 \mathrm{~km}$ downstream from the source-. The plume appears to be restricted at present in the vertical dimension between the water table 
(60 $\mathrm{m}$ depth) and $120 \mathrm{~m}$ depth, due to the presence of an impermeable layer at ca. $120 \mathrm{~m}$ depth, although there is some indication that the plume has broken through this layer to deeper levels in at least one place. The primary remediation issue here is the TCE contamination of the aquifer water. The radionuclides are of secondary concern, partly because they appear to be strongly retarded in the plume. The regulatory goals are to eliminate the source of the contamination, defined as the $5000 \mu \mathrm{g} / \mathrm{l}$ concentration isograd of TCE, and to decrease the remaining contamination to below the MCL for TCE $(5 \mu \mathrm{g} / \mathrm{l})$. The present remediation work is by pumping and treating. However, because TCE is relatively insoluble, the rate of removal of TCE from the ground is small. Removal of the contamination source will probably entail extraction or in situ destruction of TCE by some form of oxidation. Reduction of the plume TCE concentration to below MCL may also require some form of in situ destruction of TCE unless n\&al attenuation is shown to be sufficient.

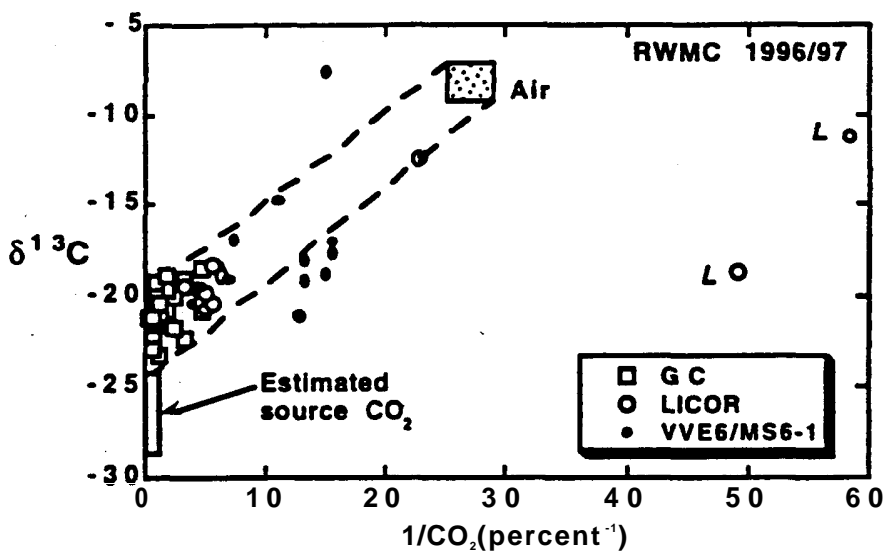

Figure 1. Relationship between the $\mathrm{CO}_{2}$ concentration and the ${ }^{13} \mathrm{C} /{ }^{2} \mathrm{C}$ ratio of the $\mathrm{CO}_{2}$ in subsurface gas at RWMC; the ${ }^{13} \mathrm{C} /{ }^{12} \mathrm{C}$ ratio is expressed as $\delta{ }^{13} \mathrm{C}$. The samples with the highest $\mathrm{CO}_{2}$ concentrations have the lowest $\delta{ }^{13} \mathrm{C}$, indicating that the $\mathrm{CO}_{2}$ is being produced by oxidation of organic carbon. The corresponding to the intercept $\left(\mathrm{CO}_{2}\right)^{-1}=0$ is normally about 4 permil higher than the $\delta^{13} \mathrm{C}$ of the source carbon (Cerling et al., GCA 55,3403, $1991)$, so the carbon source probably has $\delta{ }^{13} \mathrm{C}$ slightly below -25 . This value corresponds closely to that of typical lubricating oils buried at the site, but not to chlorinated solvents, which normally have lower $\delta^{13} \mathrm{C}$ values of -23 to 50. Data labelled ' $\mathrm{L}$ " are examples of sampling artifacts caused by leakage of the sample bags during shipping. There is a suggestion that the $\mathrm{CO}_{2}$ in the background wells (VVE-6, M6S)is partly from a source with lower $\delta{ }^{13} \mathrm{C}$.

\subsection{Subsurface disposal area (SDA) of the Radioactive Waste Management Complex (RWMC)}

Volatile organic compound (VOC) contaminants are present in the vadose zone beneath and within the immediate vicinity of the Subsurface Disposal Area (SDA) of the Radioactive waste Management Complex (RWMC) (see Figures 2,3, and 4). Depth to the water table is greater than $150 \mathrm{~m}$, with perched water above sediment\&y interbeds. The source of contamination is 88,000 gal of organic waste disposed of in various pits and trenches in the SDA from 1966 to 1970. Wastes in pits include drums with mixtures of chlorinated solvents $\left(\mathrm{CCl}_{4}, \mathrm{TCA}, \mathrm{PCE}, \mathrm{TCE}\right)$ and lubricating oil. Leakage from the drums has resulted in a plume of contaminants and possible metabolic byproducts (e.g., chloroform, vinyl chloride) in the vadose zone. It is believed that the VOCs are mainly in rubble zones and highly permeable fractures in the basalt host- 


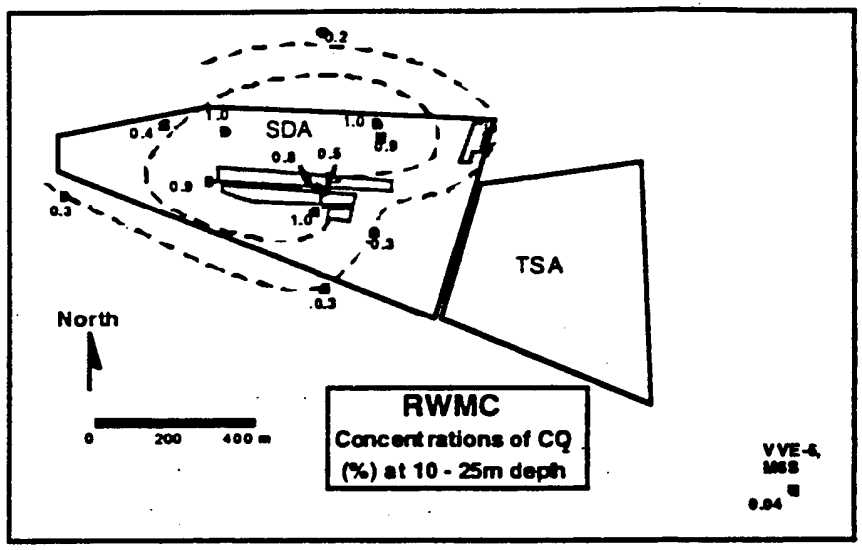

Figure 2. Map of the Radioactive Waste Management Complex at INEEL, showing locations of wells where gas samples were obtained for isotopic analysis during the period November 1996-June 1997. Numbers shown are concentrations of $\mathrm{CO}_{2}$ in percent; contours are shown at about 0.3 and $0.5 \%$. The wells to the southeast (WE- 6 and M6S) were sampled to represent "background values." $\mathrm{A} \mathrm{CO}_{2}$ concentration of $1 \%$ is about 30 times the atmospheric value, and about 20 times the subsurface background value.

Present remedial activities use a vapor vacuum extraction (WE) technique to 'withdraw the contaminants from the vadose zone so they can be treated and disposed of at the surface (Figures 3 and 4). Successful remediation depends on understanding vapor flow in the vadose zone. High permeability features may act as preferential fast flow paths that affect the efficiency of the VVE process. Other issues concern whether VOCs are being continually released as they are being pumped out, at what rate, and whether the VOCs are being naturally remediated by biological activity or other types of reactions.

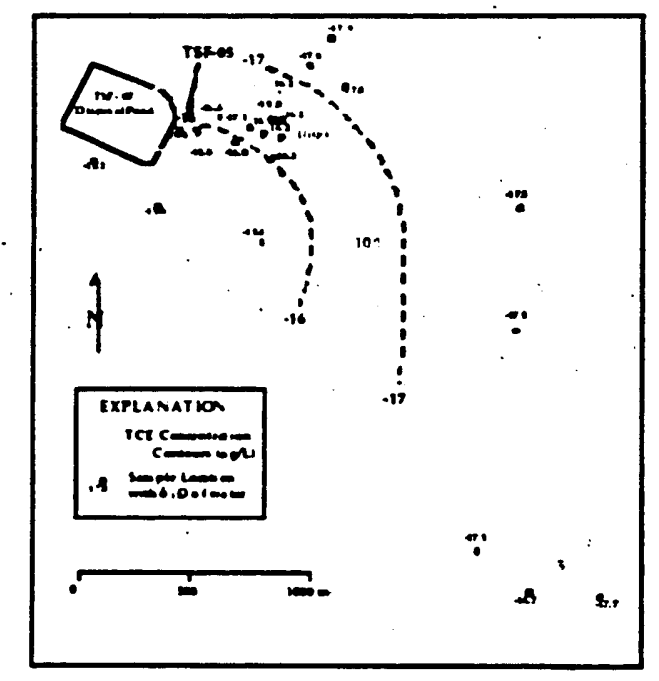

Figure 3. Map of the Test Area North (TAN) site at INEEL, showing TCE plume and $\delta{ }^{18} \mathrm{O}$ values of groundwaters sampled in summer 1997. The waters with $\delta{ }^{18} \mathrm{O}$ values greater than -16.5 show evidence of evaporation and may be affected by infiltration below the TSF-07 disposal pond. The waters with high $\quad \delta{ }^{18} \mathrm{O}$ also have low $\delta{ }^{13} \mathrm{C}$ in dissolved inorganic carbon, an effect that may be indicative of active biodegradation of organic material. 


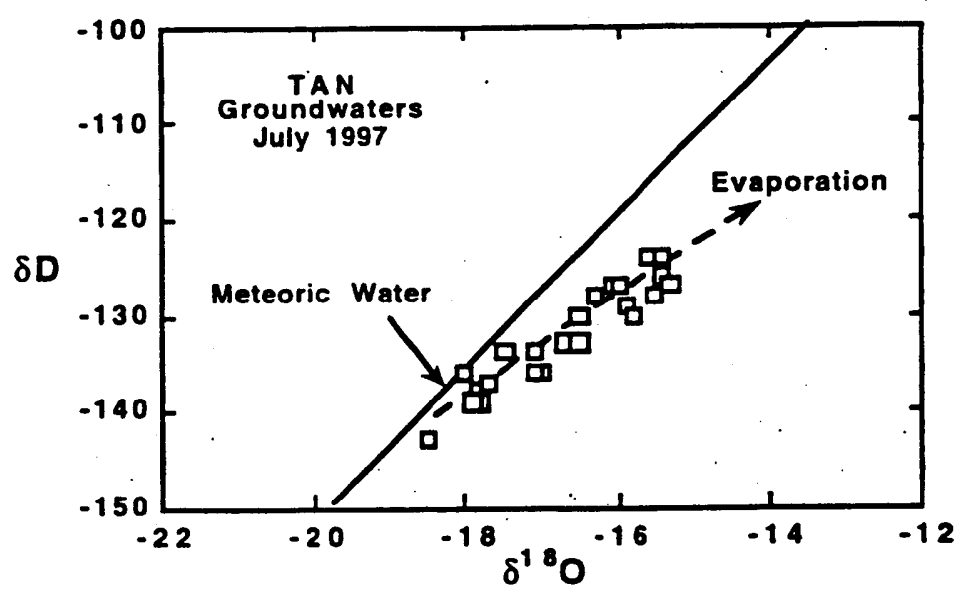

Figure 4. The $\delta{ }^{18} \mathrm{O}$ and $\delta \mathrm{D}$ values of TAN groundwaters indicate that they contain a component of water that has been affected by evaporation. Evaporation causes there to be a different relationship between ${ }^{1{ }^{18}} \mathrm{O}$ and $\delta \mathrm{D}$ than observed for normal meteoric waters.

\subsection{SAM PLING}

Application of the isotopic techniques requires field sampling and the return of the samples to the laboratory for analysis. At RWMC, vadose zone gas samples are obtained routinely formonitoring of $\mathrm{CCl}_{4}$ and other contaminants. The sampling is done via a series of monitoring wells that surround the site of the buried materials. Wells located relatively far from the burial trenches penetrate to the water table whereas those close to the burial trenches penetrate to about $200 \mathrm{ft}$ in d $\quad$ e $\quad p \quad t \quad h$.

The character of subsurface gas at RWMC varies seasonally and with the operation of the VVE system, so it is necessary to sample the system relatively often to characterize it. A subset of samples from the normal weekly monitoring of RWMC was sent to us at LBNL in November 1996, February 1997, March 1997, and June 1997. The sampling is continuing. A set of water samples from TAN groundwater was sent to us in July of 1997. The TAN groundwater plume evolves on a much slower time scale than the RWMC vadose zone plume, so sampling needs to be done only a few times during the course of the study.

\subsection{Measurements}

The RWMC gas samples have been measured for ${ }^{13} \mathrm{C} /{ }^{12} \mathrm{C}$ ratios, ${ }^{14} \mathrm{C} /{ }^{12} \mathrm{C}$ ratios, and the concentrations of $\mathrm{CO}_{2}, \mathrm{O}_{2}$, and $\mathrm{N}_{2}$. Noble gas concentration and isotopic analyses are planned but have not yet been carried out. TAN water samples have so far been measured for ${ }^{13} \mathrm{C} /{ }^{12} \mathrm{C}$ ratios, ${ }^{18} \mathrm{O} /{ }^{16} \mathrm{O}$ ratios, $\mathrm{D} / \mathrm{H}$ ratios and the concentration of dissolved inorganic carbon (DIC). Measurements of ${ }^{87} \mathrm{Sr} /{ }^{86} \mathrm{Sr}$ and ${ }^{14} \mathrm{C} /{ }^{12} \mathrm{C}$ ratios of TAN waters are underway. 


\section{$5.0 \quad$ R eSULts}

- There is substantial production of $\mathrm{CO}_{2}$ in the subsurface of the RWMC site. This production is far above the background values that can be observed outside from the Subsurface Disposal Area (SDA; Figure 2). The vadose zone $\mathrm{CO}_{2}$ has a low ${ }^{13} \mathrm{Cl}^{12}$ ratio and therefore appears to be an oxidation product of organic material (Figure 2). It is not yet possible to determine with confidence which organic material is being oxidized and by what mechanism, but our preliminary assessment is that the source of the $\mathrm{CO}_{2}$ is oxidation of the lubricating oil rather than oxidation of the chlorinated solvents.

- Initial ${ }^{14} \mathrm{C}$ analyses of the $\mathrm{CO}$, indicate the presence of an additional, radioactive source for the $\mathrm{CO}$, in the vadose zone of RWMC. This source is tentatively identified as buried reflector blocks from nuclear reactors. Evidence of migration of the ${ }^{14} \mathrm{C}$ is found in the "background" monitoring well about $1 \mathrm{~km}$ southeast of the trenches.

- A map of the $\delta{ }^{18} \mathrm{O}$ and $\delta \mathrm{D}$ values of groundwater at TAN indicate a region near and to the south of the injection well that has relatively high $\delta{ }^{18} \mathrm{O}$ (Figure 3). These waters also have $\delta \mathrm{D}$ values that indicate they have been subject to evaporation (Figure 4). These isotopic data indicate a significant contribution of evaporated water, presumably from the TSF-07 disposal pond.

- The $\delta{ }^{13} \mathrm{C}$ values of TAN groundwater DIC are 2-3\%o lower in the vicinity of the plume, indicating a possible contribution from degradation of contaminants (Figure 5).

- Analysis of $\delta{ }^{18} \mathrm{O}$ and $\delta{ }^{13} \mathrm{C}$ in TAN groundwater from below the lower confining layer of the upper aquifer suggests that there is no exchange across the lower confining layer.

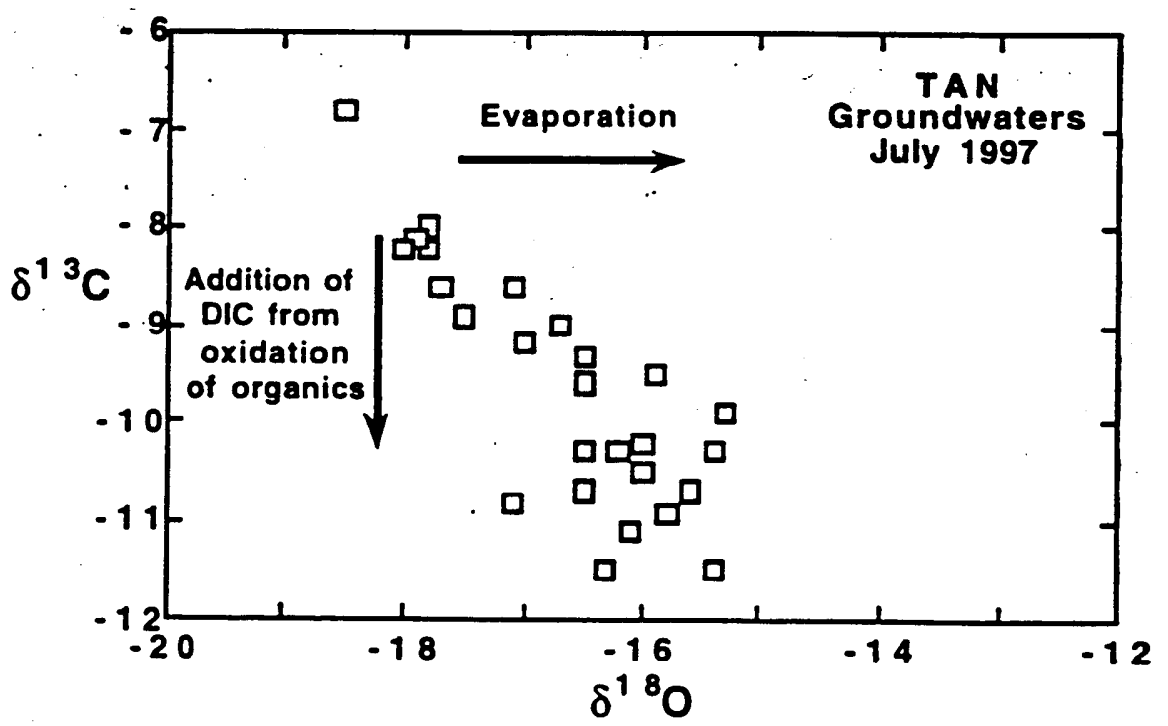

Figure 5. Relationship between carbon and oxygen isotopic composition in TAN waters. The low $\delta{ }^{13} \mathrm{C}$ values indicate a contribution to the dissolved carbon from oxidation of organic material, and this carbon is associated with the water that has been evaporated. 


\subsection{IMPLicAtion S}

The preliminary results to date confirm that isotopic analysis of groundwaters and vadose zone gases are useful for diagnosing chemical processes occurring in the subsurface, and tracing the migration of waters from different sources. At both the RWMC and TAN sites there is evidence of biodegradation of organic material in the subsurface, although the evidence to date suggests that the most problematic contaminants are not being degraded at a significant rate. This needs to be confirmed with more analytical work and modelling. 